\title{
Effect of Combined Training Protocol on Postural Control and Motor Functions of Individuals with Multiple Sclerosis
}

\author{
Behzad Najafi ${ }^{1}$, Reza Rajabi ${ }^{*}$, Foad Seidi ${ }^{1 *}$, Farhad Golipoor Maemodan ${ }^{2}$
}

1. Dept. of Sport Medicine and Health, Faculty of Physical Education and Sport Sciences, University of Tehran, Tehran, Iran

2. Dept. of Neurology, Vali-e-Asr Hospital, Zanjan University of Medical Sciences, Zanjan, Iran

\begin{tabular}{|c|c|}
\hline \multirow{2}{*}{$\begin{array}{l}\text { Article Info } \\
\text { doi } 10.30699 / \text { jambs.27.122.43 }\end{array}$} & ABSTRACT \\
\hline & Background \& Objective: Multiple Sclerosis (MS) is a common chronic \\
\hline $\begin{array}{l}\text { Received: 2018/08/09; } \\
\text { Accepted: 2019/03/07; } \\
\text { Published Online: } 10 \text { May 2019; }\end{array}$ & $\begin{array}{l}\text { function disorders are the most common MS related symptoms. Currently, exercise } \\
\text { therapy seems to be the most effective non-pharmacological approach in controlling } \\
\text { and improving these disorders. Thus, the present study intends to study the effect of }\end{array}$ \\
\hline $\begin{array}{l}\text { Use your device to scan and read the } \\
\text { article online }\end{array}$ & $10 \mathrm{~s}$ \\
\hline \multirow{3}{*}{ 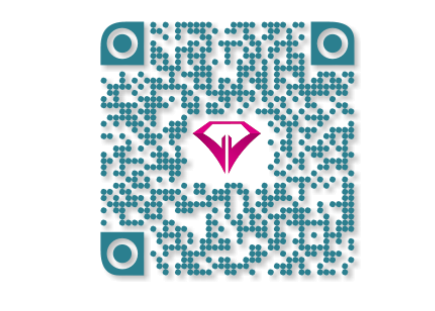 } & $\begin{array}{l}\text { Materials \& Methods: After selecting } 60 \text { women with MS as the study sample, they } \\
\text { were randomly assigned to two training intervention and control groups, each } \\
\text { comprised of } 30 \text { subjects. The training intervention group performed the combined } \\
\text { training protocol for eight weeks. }\end{array}$ \\
\hline & $\begin{array}{l}\text { Results: The results of the covariance analysis showed that the combined training } \\
\text { protocol had a significant effect on all postural control (postural sway indexes and } \\
\text { Berg Balance Scale) and motor function (Timed } 25 \text { Feet Walk test and Timed Up and } \\
\text { Go test) variables in individuals with MS ( } P \leq 0.05) \text {. }\end{array}$ \\
\hline & Conclusion: The results of this study indicated that the combined training protoco \\
\hline \multirow{2}{*}{$\begin{array}{l}\text { Corresponding Information: } \\
\text { Rajabi R and Seidi F, Dept. of Sport } \\
\text { Medicine and Health, Faculty of Physical } \\
\text { Education and Sport Sciences, University of } \\
\text { Tehran, Tehran, Iran } \\
\text { Email: rrajabi@ut.ac.ir } \\
\text { Email: foadseidi@ut.ac.ir }\end{array}$} & $\begin{array}{l}\text { improved postural control and motor functions of individuals with MS. Therefore } \\
\text { these results may be recommended to all individuals who are making an effort to treat } \\
\text { and improve individuals with MS. }\end{array}$ \\
\hline & $\begin{array}{l}\text { Keywords: Multiple Sclerosis, Postural Control, Motor Function, Combined } \\
\text { Training Protocol }\end{array}$ \\
\hline \multirow[t]{2}{*}{ 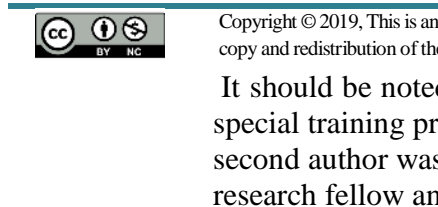 } & $\begin{array}{l}\text { 1-access article distributed under the terms of the Creative Commons Attribution-noncommercial } 4.0 \text { International License which permits } \\
\text { tin noncommercial usages with proper citation. }\end{array}$ \\
\hline & $\begin{array}{l}\text { cording to the nature of this research and the necessity of an expert to planning a } \\
\text { or individuals with MS, two authors were named as the corresponding authors. The } \\
\text { search fellow, methodologist and statistical consultant and the third author was as a } \\
\text { ng protocol consultant. }\end{array}$ \\
\hline
\end{tabular}

\section{Introduction}

Multiple Sclerosis (MS) is a common chronic inflammatory disease of the central nervous system, which typically affects young adults aged between 20 and 40 years of age. According to the most recent official studies published in 2014, approximately 2.5 million people suffer from MS all over the world (1). Numerous studies indicate a significant increase in the last two decades in the occurrence and prevalence of MS in Iran (2). Iran accounts for the highest occurrence and prevalence rate of MS in Asia and the Middle East (3). The latest MS census had approximately 70,000 cases in Iran in 2016, and in 2017, with about 148 cases per 100,000 people in Tehran (4). MS results in the demyelination and neural damage of the central nervous system, which results in different manifestations. Among the most commonly seen disorders of MS are postural control and motor function disorders, especially gait disorders, fatigue, muscle weakness, pain, leg spasticity and visual disorders $(5,6)$. MS, senility and/or musculoskeletal disorders are some of the key factors that negatively affect the efficiency of the postural control system (7). Postural control is a complicated process that depends on the coordination of several sensory, motor, and biomechanical components which are influenced by visual, vestibular, and somatosensory systems with mutual effect on the central nervous system (8).

Results of various studies indicate that about 75 to 85 percent of individuals with MS have postural control disorder and postural instability (9), which has been noted as a risk factor in the increase of falling risk in individuals with MS (10). Motor function disorder, especially gait disorder, is one of the most common disorders and symptoms of individuals with MS, which is seen in approximately 80 percent of MS patients (6). 
Nowadays, there are a lot of studies about the positive effects of physical and sport activities on MS patients. Currently, exercise therapy seems to be the most effective non-pharmaceutical method to control symptoms of MS. Studies indicated that appropriate training interventions could be used to improve postural control and the motor function of individuals with MS (9). In a study, Forsberg et al. (2016) found a significant difference in balance improvement and gait in individuals with MS after the performance of training intervention (11). Although Normann et al. (2016) suggested that core stability exercise was an effective and feasible method for the rehabilitation of individuals with MS (12). Various studies suggested that training interventions (resistance or balance) had numerous benefits for postural control and motor function of the individuals with MS (12-14). In spite of the availability of the various studies, there are few scientific evidences in this regard and various authors recommended further studies on the topic (1). Thus, the present study intends to investigate the effect of combined training protocol on postural control and motor function of the individuals with MS.

\section{Materials and Methods}

The present study has been approved by the National Biomedical Research Ethics Committee (IR.UT.SPORT .REC.1397.001) and by the Iranian Registry of Clinical Trials (IRCT20170115031954N1.). This study is an applied quasi-experimental research including a pretest and posttest of the experimental and control group investigating the effect of combined training protocol on postural control and motor function of individuals with MS. The statistical population of the present study includes individuals with MS who had files in the MS Society of Zanjan by the year 2017. From amongst this population, 60 women with MS were purposively selected as the sample under supervision of a specialist considering the inclusion criteria, and randomly assigned to two training intervention and control groups, each comprised of 30 subjects. The inclusion criteria included: relapsing-remitting MS diagnosed by a neurologist $(\mathbf{1 5}, 16)$, expanded disability status between 1 and 4/5 as diagnosed by a neurologist (MS fellowship), aged between 30 and 45 years, and a history of an MS diagnosis of more than one year. The exclusion criteria included: a history of other neurological diseases and disorders such as stroke, vestibular disorder $(13,15,16)$, disease relapse within the last three months (15-17), a history of cardiovascular and pulmonary diseases $(\mathbf{1 5 , 1 6 )}$, comorbid musculoskeletal disorders and abnormalities in the spine and lower extremities $(15,16)$, using aids for gait and other daily activities, lack of normal vision or vision correction by glasses $(15,16)$, pregnancy at the time of study $(13,16)$, explicit and severe cognitive disorders (17), regular training program within the last three months (13), participation in other exercise therapy interventions, physical therapy and/or massage at the time of study (15), relapse of disease at the time of study, and irregular participation and excessive absence from training sessions. In this study, Zebris Force Distribution Measuring System (FDM-s), Zebris, Germany, and Berg Balance Scale (BBS) were used to measure postural control. Zebris Force Distribution Measuring System measures postural control based on the postural sway indexes (sway area of body's center of pressure in square millimeter and sway path length of body's center of pressure in millimeter). Three tests were taken for each task, with a twenty seconds test duration and a one-minute rest period between the two tests. Tasks were randomly tested in two open-eye and closed-eye positions.

The Berg Balance Scale was used to quantitatively and functionally assess the postural control of the subjects (18). In order to measure motor function, timed 25 Feet Walk (T25FW) and Timed Up and Go (TUG) were used. In Timed 25 Feet Walk Test, the subject was asked to safely walk the specified distance at the maximum speed with regular and normal steps with the recorded time as the subject's score (17). In the Timed Up and Go Test, the subject was seated on a normal armchair, leaning on the back of the chair, with a seat height of $45 \mathrm{~cm}$. As soon as the examiner would say "Go", the subject was asked to stand up and complete the test (14).

After pretest, the training intervention group performed the combined training protocol for eight weeks according to the specified instructions specified of the study design. It is necessary to note that after the completion of eight-weeks of study training protocol and posttest, two subjects from the intervention and control groups were excluded from the study process due to various reasons such as the relapse of disease, excessive absence, etc.

Training Protocol: The training protocol of this study is a set of applied, performable, effective, accessible, and safe exercises which include functional daily activities effective in the improvement of the study variables. The training protocol of this study focused on the improvement of postural control and motor function disorders in individuals with MS. The training intervention exercises of this study included different sensory positions, levels, and multiple motor patterns. The first part of the training intervention included stability exercises for the body's score muscles. The second part included exercises specific to postural control. These exercises tried to challenge and strengthen postural control in the form of functional activities by making changes to somatosensory, visual, and vestibular inputs. All exercises of the training protocol were purposively designed based on scientific findings. Progress in the training protocol was regulated in graduation and in consideration of the overload principle. In addition, unlike most studies, this study's training protocol was designed in compliance to the FITT (Frequency, Intensity, Time and Type) Principle $(11,12,17)$. The training protocol of this study included three weekly sessions for 8 consecutive weeks, with each session lasting approximately 60 to 80 minutes. Each training session of the training protocol had three 
sections. The initial warmup was approximately 10 minutes, which included simple static stretching exercises and aerobic exercises with a sixty-percent maximal heartbeat. The special exercise performances of this study's training protocol consisted of approximately 45 to 60 minutes. The cool down exercises lasted for approximately 5 minutes. Exercises of this protocol were designed in three initial, improvement and maintenance phases (Table 3).

Finally, data was analyzed in two descriptive and inferential statistics sections in SPSS 20 (SPSS. Inc. Chicago, Illinois, USA). In order to confirm the normal distribution of data, Kolmogorov-Smirnov (K-S) Test was used $(P \geq 0.05)$. Independent t-test was used for determining homogeneity of the groups by age, height, and weight indexes. The Mann-Whitney U Test was used for the expanded disability status. Furthermore, the Analysis of Covariance Test (ANCOVA) was used in order to investigate the effect of combined training protocol on postural control and motor function variables and compare the obtained results of the study groups. It is necessary to note that the significance level was considered at $95 \%$, with $\alpha \leq 0.05$ throughout the study.

\section{Results}

The information related to the study samples and the statistical analysis results are provided in Tables 1 and 2 , respectively. It is necessary to mention that results in Table 1 show no significant difference between the two groups and both groups are homogenous with respect to these variables $(P \geq 0.05)$.

As provided in Table 2, the results of the Analysis of Covariance Test indicate that the combined training protocol has a significant effect on all postural control (postural sway indexes and Berg Balance Scale) and motor function (Timed 25 Feet Walk Test and Timed Up and Go Test) variables in the individuals with MS $(P \leq 0.05)$.

Table 1. Demographics of Study Samples by Group (Mean \pm Standard Deviation)

\begin{tabular}{|c|c|c|c|}
\hline & $\begin{array}{c}\text { Training Intervention Group } \\
\text { (28 Subjects) }\end{array}$ & $\begin{array}{l}\text { Control Group } \\
\text { (28 Subjects) }\end{array}$ & P-value \\
\hline Age (year) & $38.39 \pm 4.59$ & $36.36 \pm 3.54$ & 0.069 \\
\hline Height $(\mathrm{cm})$ & $159.85 \pm 3.31$ & $157.92 \pm 4.27$ & 0.065 \\
\hline Weight $(\mathrm{kg})$ & $66.63 \pm 9.56$ & $61.26 \pm 11.36$ & 0.061 \\
\hline Expanded Disability Severity Scale & $2.51 \pm 1.22$ & $2.44 \pm 0.77$ & 0.746 \\
\hline
\end{tabular}

Table 2. Descriptive Statistics and Results of Analysis of Covariance of Means of Two Training Intervention and Control Groups

\begin{tabular}{|c|c|c|c|c|c|c|c|c|c|c|}
\hline \multirow{2}{*}{ Variable } & & & \multicolumn{2}{|c|}{ Training Intervention Group } & \multicolumn{2}{|c|}{ Control Group } & \multirow{2}{*}{$\begin{array}{l}\text { Degree of } \\
\text { Freedom }\end{array}$} & \multirow{2}{*}{$\begin{array}{l}\text { Mean } \\
\text { Squared }\end{array}$} & \multirow{2}{*}{$\mathbf{F}$} & \multirow{2}{*}{$\begin{array}{c}\text { Significance } \\
\text { Level }\end{array}$} \\
\hline & & & Pretest & Posttest & Pretest & Posttest & & & & \\
\hline \multirow{5}{*}{$\begin{array}{r}\text { Postural } \\
\text { Control }\end{array}$} & \multirow{2}{*}{$\begin{array}{l}\text { Postural } \\
\text { sway indexes } \\
\text { in standing } \\
\text { position with } \\
\text { open eyes }\end{array}$} & $\begin{array}{l}\text { Sway Area } \\
\text { of body's } \\
\text { center of } \\
\text { pressure }\end{array}$ & $85.58 \pm 56.40$ & $70.21 \pm 45.88$ & $60.06 \pm 37.25$ & $84.19 \pm 53.61$ & 1 & 17716.68 & 26.66 & 0.001 \\
\hline & & $\begin{array}{l}\text { Sway path } \\
\text { length of } \\
\text { body's } \\
\text { center of } \\
\text { pressure }\end{array}$ & $224.24 \pm 65.55$ & $205.45 \pm 65.97$ & $201.99 \pm 56.76$ & $211.59 \pm 54.92$ & 1 & 8640.25 & 9.34 & 0.004 \\
\hline & \multirow{2}{*}{$\begin{array}{l}\text { Postural } \\
\text { sway indexes } \\
\text { in standing } \\
\text { position with } \\
\text { closed eyes }\end{array}$} & $\begin{array}{l}\text { Sway Area } \\
\text { of body's } \\
\text { center of } \\
\text { pressure }\end{array}$ & $120.29 \pm 85.19$ & $98.53 \pm 68.37$ & $91.71 \pm 61.09$ & $121.25 \pm 77.75$ & 1 & 29378.75 & 19.29 & 0.001 \\
\hline & & $\begin{array}{l}\text { Sway path } \\
\text { length of } \\
\text { body's } \\
\text { center of } \\
\text { pressure }\end{array}$ & $306.24 \pm 134.01$ & $265.56 \pm 88.72$ & $283.24 \pm 135.36$ & $282.96 \pm 112.83$ & 1 & 11085.66 & 4.51 & 0.021 \\
\hline & \multicolumn{2}{|c|}{ Berg Balance Scale } & $41.10 \pm 8.31$ & $45.03 \pm 6.43$ & $43.96 \pm 6.51$ & $41.64 \pm 6.53$ & 1 & 425.07 & 49.54 & 0.001 \\
\hline \multirow{2}{*}{$\begin{array}{l}\text { Motor } \\
\text { Function }\end{array}$} & \multicolumn{2}{|c|}{ Timed 25 Feet Walk Test } & $5.48 \pm 1.26$ & $4.42 \pm 1.30$ & $5.36 \pm 1.22$ & $5.03 \pm 1.07$ & 1 & 6.78 & 10.51 & 0.002 \\
\hline & \multicolumn{2}{|c|}{ Timed Up and Go Test } & $8.45 \pm 2.31$ & $6.64 \pm 1.92$ & $7.54 \pm 1.51$ & $7.77 \pm 1.76$ & 1 & 46.46 & 50.91 & 0.001 \\
\hline
\end{tabular}


Table 3. Training Protocol

\begin{tabular}{|c|c|c|c|c|c|c|c|c|c|c|c|}
\hline \multirow[b]{2}{*}{ Phase } & \multirow{2}{*}{\multicolumn{2}{|c|}{ WEEK }} & \multicolumn{9}{|c|}{ EXERCISES } \\
\hline & & & \multicolumn{2}{|c|}{$\begin{array}{c}\text { EXERCISE } \\
\text { NO. } 1 \\
\text { (FULL } \\
\text { PLANK) }\end{array}$} & $\begin{array}{c}\text { EXERCISE } \\
\text { NO. } 2 \\
\text { (SIDE } \\
\text { PLANK) }\end{array}$ & \multicolumn{2}{|c|}{$\begin{array}{c}\text { EXERCISE No. } 3 \\
\text { (ABDOMINAL } \\
\text { BRIDGE) }\end{array}$} & \multicolumn{2}{|r|}{$\begin{array}{c}\text { EXERCISE No. } \\
\text { (BIRD DOG) }\end{array}$} & \multicolumn{2}{|c|}{$\begin{array}{c}\text { ExERCISE No. } \\
5 \\
\text { (DIAGONAL } \\
\text { CRUNCH) }\end{array}$} \\
\hline INITIAL & \multicolumn{2}{|r|}{1} & $\begin{array}{c}3 \times 10 \\
\text { FIGURE } 1\end{array}$ & & $\begin{array}{l}3 \times 10 \\
\text { FIGURE } 2-1\end{array}$ & \multicolumn{2}{|c|}{$\begin{array}{l}3 \times 12 \\
\text { FIGURE 3-1 }\end{array}$} & & $\begin{array}{c}3 \times 12 \\
\text { FIGURE } 4-1\end{array}$ & \multicolumn{2}{|r|}{$\begin{array}{c}3 \times 10 \\
\text { FIGURE 5-1 }\end{array}$} \\
\hline \multirow{5}{*}{$\begin{array}{c}\text { IMPROVEME } \\
\text { NT }\end{array}$} & \multicolumn{2}{|r|}{2} & \multicolumn{2}{|c|}{$\begin{array}{l}\text { FIGURE } 1-1 \\
\text { FIGURE } 10\end{array}$} & $\begin{array}{l}\quad 4 \times 10 \\
\text { FIGURE } 2-1\end{array}$ & & $\begin{array}{l}\times 12 \\
\text { JRE } 3-1\end{array}$ & & $\begin{array}{c}4 \times 12 \\
\text { FIGURE } 4-1\end{array}$ & & $\begin{array}{c}4 \times 10 \\
\text { FIGURE 5-1 }\end{array}$ \\
\hline & \multicolumn{2}{|r|}{3} & \multicolumn{2}{|c|}{$\begin{array}{l}4 \times 10 \\
\text { FIGURE } 1-1\end{array}$} & $\begin{array}{c}4 \times 10 \\
\text { FIGURE 2-1 }\end{array}$ & \multicolumn{2}{|c|}{$\begin{array}{c}4 \times 12 \\
\text { FIGURE } 3-1\end{array}$} & \multicolumn{2}{|r|}{$\begin{array}{c}4 \times 12 \\
\text { FIGURE } 4-1\end{array}$} & \multicolumn{2}{|r|}{$\begin{array}{l}4 \times 10 \\
\text { FIGURE 5-1 }\end{array}$} \\
\hline & \multicolumn{2}{|r|}{4} & \multicolumn{2}{|c|}{$\begin{array}{c}4 \times 10 \\
\text { FIGURE } 1-2\end{array}$} & $\begin{array}{l}4 \times 10 \\
\text { FIGURE } 2-2\end{array}$ & \multicolumn{2}{|c|}{$\begin{array}{c}4 \times 12 \\
\text { FIGURE } 3-2\end{array}$} & \multicolumn{2}{|r|}{$\begin{array}{l}4 \times 12 \\
\text { FIGURE 4-2 }\end{array}$} & \multicolumn{2}{|r|}{$\begin{array}{l}4 \times 10 \\
\text { FIGURE 5-2 }\end{array}$} \\
\hline & \multicolumn{2}{|r|}{5} & \multicolumn{2}{|c|}{$\begin{array}{c}4 \times 10 \\
\text { FIGURE } 1-2\end{array}$} & $\begin{array}{c}4 \times 10 \\
\text { FIGURE } 2-2\end{array}$ & \multicolumn{2}{|c|}{$\begin{array}{l}4 \times 12 \\
\text { FIGURE 3-2 }\end{array}$} & \multicolumn{2}{|r|}{$\begin{array}{l}4 \times 12 \\
\text { FIGURE 4-2 }\end{array}$} & & $\begin{array}{c}4 \times 10 \\
\text { FIGURE 5-2 }\end{array}$ \\
\hline & & 6 & $\begin{array}{c}4 \times 12 \\
\text { FIGURE } 1\end{array}$ & & $\begin{array}{c}4 \times 12 \\
\text { FIGURE } 2-3\end{array}$ & & $\begin{array}{l}\times 15 \\
\text { JRE } 3-3\end{array}$ & & $\begin{array}{c}4 \times 15 \\
\text { FIGURE } 4-3\end{array}$ & & $\begin{array}{l}4 \times 12 \\
\text { FIGURE 5-3 }\end{array}$ \\
\hline MAINTENA & & 7 & $\begin{array}{c}4 \times 12 \\
\text { FIGURE } 1\end{array}$ & & $\begin{array}{l}4 \times 12 \\
\text { FIGURE } 2-3\end{array}$ & & $\begin{array}{l}\times 15 \\
\text { JRE } 3-3\end{array}$ & & $\begin{array}{l}4 \times 15 \\
\text { FIGURE 4-3 }\end{array}$ & & $\begin{array}{l}4 \times 12 \\
\text { FIGURE 5-3 }\end{array}$ \\
\hline NCE & & 8 & $\begin{array}{l}4 \times 12 \\
\text { FIGURE } 1\end{array}$ & & $\begin{array}{c}4 \times 12 \\
\text { FIGURE } 2-3\end{array}$ & & $\begin{array}{l}\times 15 \\
\text { JRE 3-3 }\end{array}$ & & $\begin{array}{l}4 \times 15 \\
\text { FIGURE 4-3 }\end{array}$ & & $\begin{array}{l}4 \times 12 \\
\text { FIGURE 5-3 }\end{array}$ \\
\hline & & & & & & & rcises & & & & \\
\hline Phase & $\begin{array}{c}\text { Wee } \\
\mathrm{k}\end{array}$ & $\begin{array}{c}\text { Exerci } \\
\text { se No. } \\
6 \\
\text { (Walk) } \\
\text { Figure } \\
\text { 6-1 }\end{array}$ & $\begin{array}{c}\text { Exercise } \\
\text { No. 6 } \\
\text { (Walk) } \\
\text { Figure 6- } \\
\quad 2\end{array}$ & $\begin{array}{c}\text { Exercis } \\
\text { e No. 6 } \\
\text { (Walk) } \\
\text { Figure } \\
\mathbf{6 - 3}\end{array}$ & $\begin{array}{c}\text { Exercise } \\
\text { No. 6 } \\
\text { (Walk) } \\
\text { Figure 6- } \\
\quad 4\end{array}$ & $\begin{array}{c}\text { Exercis } \\
\text { e No. } 7 \\
\text { (Tande } \\
\text { m) } \\
\text { Figure } \\
7-1\end{array}$ & $\begin{array}{c}\text { Exercis } \\
\text { e No. } 7 \\
\text { (Tande } \\
\text { m) } \\
\text { Figure } \\
7-2\end{array}$ & $\begin{array}{c}\text { Exercise } \\
\text { No. } 7 \\
\text { (Tande } \\
\text { m) } \\
\text { Figure } \\
7-3\end{array}$ & $\begin{array}{c}\text { Exercise } \\
\text { No. 8 } \\
\text { (Standing } \\
\quad \text { ) } \\
\text { Figure 8- } \\
\quad 1\end{array}$ & $\begin{array}{c}\text { Exercise } \\
\text { No. 8 } \\
\text { (Standin } \\
\text { g) } \\
\text { Figure 8- } \\
\quad 2\end{array}$ & $\begin{array}{c}\text { Exercise } \\
\text { No. 8 } \\
\text { (Standing) } \\
\text { Figure 8-3 }\end{array}$ \\
\hline Initial & 1 & $\begin{array}{l}3 \times 20 \\
\text { Open }\end{array}$ & $\begin{array}{l}3 \times 15 \\
\text { Open }\end{array}$ & $\begin{array}{l}3 \times 15 \\
\text { Open }\end{array}$ & --- & $\begin{array}{l}3 \times 15 \\
\text { Open }\end{array}$ & --- & --- & --- & --- & --- \\
\hline & 2 & $\begin{array}{l}4 \times 20 \\
\text { Open }\end{array}$ & $\begin{array}{l}4 \times 15 \\
\text { Open }\end{array}$ & $\begin{array}{l}4 \times 15 \\
\text { Open }\end{array}$ & --- & $\begin{array}{l}4 \times 15 \\
\text { Open }\end{array}$ & --- & --- & --- & --- & --- \\
\hline & 3 & $\begin{array}{l}4 \times 20 \\
\text { Open }\end{array}$ & $\begin{array}{l}4 \times 15 \\
\text { Open }\end{array}$ & $\begin{array}{l}4 \times 15 \\
\text { Open }\end{array}$ & $\begin{array}{l}3 \times 15 \\
\text { Open }\end{array}$ & $\begin{array}{l}4 \times 15 \\
\text { Open }\end{array}$ & $\begin{array}{l}3 \times 15 \\
\text { Open }\end{array}$ & --- & --- & --- & --- \\
\hline Improvement & 4 & $\begin{array}{l}3 \times 20 \\
\text { Open, } \\
\text { Closed }\end{array}$ & $\begin{array}{l}3 \times 15 \\
\text { Open, } \\
\text { Closed }\end{array}$ & $\begin{array}{l}3 \times 15 \\
\text { Open, } \\
\text { Closed }\end{array}$ & $\begin{array}{l}3 \times 15 \\
\text { Open }\end{array}$ & $\begin{array}{l}3 \times 15 \\
\text { Open, } \\
\text { Closed }\end{array}$ & $\begin{array}{l}3 \times 15 \\
\text { Open }\end{array}$ & --- & --- & --- & --- \\
\hline & 5 & $\begin{array}{l}3 \times 20 \\
\text { Open, } \\
\text { Closed }\end{array}$ & $\begin{array}{l}3 \times 15 \\
\text { Open, } \\
\text { Closed }\end{array}$ & $\begin{array}{l}3 \times 15 \\
\text { Open, } \\
\text { Closed }\end{array}$ & $\begin{array}{l}3 \times 15 \\
\text { Open, } \\
\text { Closed }\end{array}$ & $\begin{array}{l}3 \times 15 \\
\text { Open, } \\
\text { Closed }\end{array}$ & $\begin{array}{l}4 \times 15 \\
\text { Open }\end{array}$ & $\begin{array}{l}3 \times 15 \\
\text { Open }\end{array}$ & $\begin{array}{l}3 \times 15 \\
\text { Open }\end{array}$ & --- & -- \\
\hline & 6 & $\begin{array}{l}4 \times 20 \\
\text { Open, } \\
\text { Closed }\end{array}$ & $\begin{array}{l}4 \times 15 \\
\text { Open, } \\
\text { Closed }\end{array}$ & $\begin{array}{l}4 \times 15 \\
\text { Open, } \\
\text { Closed }\end{array}$ & $\begin{array}{l}3 \times 15 \\
\text { Open, } \\
\text { Closed }\end{array}$ & $\begin{array}{l}4 \times 15 \\
\text { Open, } \\
\text { Closed }\end{array}$ & $\begin{array}{l}4 \times 15 \\
\text { Open }\end{array}$ & $\begin{array}{l}3 \times 15 \\
\text { Open }\end{array}$ & $\begin{array}{l}3 \times 15 \\
\text { Open }\end{array}$ & $\begin{array}{l}3 \times 15 \\
\text { Open }\end{array}$ & $\begin{array}{l}3 \times 15 \\
\text { Open }\end{array}$ \\
\hline & 7 & --- & --- & --- & -- & --- & --- & $\begin{array}{l}3 \times 15 \\
\text { Open, } \\
\text { Closed }\end{array}$ & $\begin{array}{l}3 \times 15 \\
\text { Open, } \\
\text { Closed }\end{array}$ & $\begin{array}{l}4 \times 15 \\
\text { Open }\end{array}$ & $\begin{array}{l}3 \times 10 \\
\text { Open, } \\
\text { Closed }\end{array}$ \\
\hline Maintenance & 8 & --- & --- & --- & -- & --- & --- & $\begin{array}{l}3 \times 15 \\
\text { Open, } \\
\text { Closed }\end{array}$ & $\begin{array}{l}3 \times 15 \\
\text { Open, } \\
\text { Closed }\end{array}$ & $\begin{array}{l}4 \times 15 \\
\text { Open }\end{array}$ & $\begin{array}{l}3 \times 10 \\
\text { Open, } \\
\text { Closed }\end{array}$ \\
\hline
\end{tabular}

* It is necessary to note that the ratio for rest between repetitions is 1 to 1 .

* It is necessary to note that in the table above, $3 \times 10$ means three sets of the concerned exercise for a 10 seconds repetition.

* It is necessary to note that the rest between repetitions is proportionate to the duration of exercises.

* It is necessary to note that in the table above, $3 \times 10$ open, closed means three sets of the concerned exercise for a 10 seconds repetition with eyes open and closed.

\section{Discussion}

The present study investigated the effect of combined training protocol on postural control and motor function of individuals with MS. The results of the present study showed that the combined training protocol had a significant effect on postural control (postural sway indexes and Berg Balance Scale) and motor function (Timed 25 Feet Walk Test and Timed
Up and Go Test) in individuals with MS and led to the improvement of these variables. The results of these changes are completely provided in Table 2.

Results of the present study are consistent with those of the study conducted by Forsberg et al. (11), Normann et al. (12) and Carling et al. (17). Upon the 
study of 73 subjects in two groups with 7-weeks of training intervention, Forsberg et al. found a significant difference in balance and gait of the training intervention group (11). Normann et al. also studied the effect of balance and core stability exercises on gait in 12 individuals with MS. After performing the exercises for 5 weeks, they reported a significant improvement in sitting balance, twenty-five-feet-walk duration, and two-minute and six-minute walks, and self-assessment scales (12). In addition, the results of the present study are inconsistent with Tomruk et al. (15), which can probably be attributed to the different training protocol of their study, the different age range and sex of the subjects, and the different measurement methods. In regard to our study and its possible reasons for the effectiveness of training intervention in the stability exercises of core muscles, it can be stated that human movement originates from the trunk which is an area of utmost importance for stability. This is because the trunk forms the largest part of the body, and due to its anatomical position, it acts as the body's center of gravity. Different studies have also mentioned the core muscle activities of the body previous to the movement of the lower extremity and assumed that the role of these muscles are necessary in the securing of stability and the creation of stable support in order to perform movements in the lower extremity (19). Results of different studies indicate that the activity of the body's core stabilizing muscles can be considered as an important and fundamental factor in effective postural control and motor function. With that said, in order improve postural control and body stability and motor function of individuals with MS, it seems necessary to include strengthening exercises of these muscles in training interventions (20). Furthermore, muscle weakness is a dominant characteristic of the disorders resulting from MS. Many studies associated muscle weakness in the lower extremity with postural control disorder, postural instability, motor function disorder, and increased disability in MS patients. These studies suggested a direct relationship between strength and postural instability in such individuals (21). Performing resistance exercises leads to neural stimulation, improved muscle strength, increased muscle tone, and improved muscle oxidative capacity (22). Due to demyelination, MS patients experience disturbed signal conduction of efferent neurons and neuromuscular adaptations, which occur as a result of resistance training, can increase the signal conduction of efferent neuron, leading to improved muscle coordination, which helps the stabilization of the body's standing position (23). Additionally, increased muscle strength is associated with an improvement in one's motor function (21). Also, due to training interventions, improved gait parameters may result from increased muscle strength and decreased spasticity of the lower extremity. This can increase control in the muscles, joints, and coordination, which leads to an improved static and dynamic stability (24). Yahia et al. (2011) found a significant relationship between postural control and motor function disorders and muscle weakness in quadriceps and hamstring muscles in MS patients, and suggested the inclusion of hamstring and quadriceps strengthening in their training interventions (25). Regarding the effectiveness of the excises specific to postural control, it can be stated, in accordance to other studies, individuals with MS have a delay in postural responses, which is correlatively related to a delay in the conduction of stimulated sensorimotor potentials. A possible reason for MS is the demyelination of the posterior spinal cord, which consequently results in delayed postural responses, leading to postural control disorder (26). The effect of balance exercise interventions is at least partially related to the role of sensorimotor inputs in postural control. In fact, motion sense, especially proprioception, is very important for the effectiveness of both postural feedback and feedforward controls and gait (27). Feedback mechanisms from afferent dataoriginating from the skin, muscles, and special senses (visual and vestibular) — dynamically form gait patterns in relation to environmental conditions. In order to cope with these environmental conditions, the central nervous system uses compensatory postural adjustments (feedback mechanisms) and/or predictive postural adjustments (feedforward mechanisms). These exercises seem to play a role in strengthening neural signals, which leads to improved postural control (27). Training interventions, with a manipulation at the visual level for further challenging postural control, may improve sensorimotor processing integration in dynamic patterns (28). Brichetto et al. (2015) suggested that performing balance training could result in the reorganization of neural networks, the improvement of the central sensory integration, and the improvement of postural control in individuals with MS (29). By changing vestibular system inputs, the performance of balance training interventions seems to provide a sufficient stimulation proportionate to the movement patterns of neural reorganization, the development of central sensory integration, and the consequently improved postural control (30). Additionally, with the change of visual system inputs, balance training interventions play a key role in neuromuscular reorganization. Since visual inputs play a key role in the performance of coordinated 
movements, these exercises seem to be effective in the postural control improvement of MS patients (30).

\section{Conclusion}

The present study aimed to study the effect of combined training protocol on postural control and motor function of individuals with MS. The results showed that the combined training protocol had a significant effect on postural control and motor function in MS patients and improved upon these variables. Therefore, considering the obtained results, such findings may be recommended to sport professionals and coaches, physicians, physical therapists, and all individuals who are attempting to treat and improve MS patients. However, in order to thoroughly improve postural control and motor function disorders in such individuals, further research is needed.

\section{Acknowledgment}

This article is an extraction from a part of a dissertation authored by Behzad Najafi under the supervision of Dr. Reza Rajabi and Dr. Foad Seidi, and under consultation of Dr. Farhad Golipoor Maemodan. I want to extend my appreciation to the supervising and consulting professors, all subjects of the study, MS Society of Zanjan Province, Faculty of Physical Education and Sport Sciences of University of Tehran, and all those who assisted in the completion this study.

\section{Conflict of Interest}

The authors declared no conflicts of interest.

\section{Funding}

$? ?$

\section{References}

1. Motl RW, Learmonth YC, Pilutti LA, Gappmaier E, Coote S. Top 10 research questions related to physical activity and multiple sclerosis. Res Q Exerc Sport. 2015;86(2):117-29. (DOI:10.1080/02701367.2015.1023099) (PMID)

2. Etemadifar M, Sajjadi S, Nasr Z, Firoozeei TS, Abtahi SH, Akbari M, Fereidan-Esfahani M. Epidemiology of multiple sclerosis in Iran: a systematic review. Eur Neurol. 2013;70(56):356-63. (DOI:10.1159/000355140) (MID)

3. Eskandarieh S, Heydarpour P, Minagar A, Pourmand S, Sahraian MA. Multiple Sclerosis Epidemiology in East Asia, South East Asia and South Asia: A Systematic Review. Neuroepidemiology. 2016;46(3):209-21. $\quad$ (DOI:10.115 9/000444019) (PMID)
4. Eskandarieh S, Molazadeh N, Moghadasi AN, Azimi AR, Sahraian MA. The prevalence, incidence and familial recurrence of multiple sclerosis in Tehran, Iran. Multiple scler Relat Disord. 2018;25:143. (DOI:10.1016/j.msard.2018.07.0 23) (PMID)

5. Davies BL, Hoffman RM, Kurz MJ. Individuals with multiple sclerosis redistribute positive mechanical work from the ankle to the hip during walking. Gait Posture. 2016;49:329-33. ．DOI:10.1016/j.gaitpost.2016.07.267) (PMID)

6. Motl RW. Ambulation and multiple sclerosis. Phys Med Rehabil Clin N Am. 2013;24(2):325-36. (DOI:10.1016/j. pmr.2012.11.004) (MID)

7. Kiers H, van Dieën JH, Brumagne S, Vanhees L. Postural sway and integration of proprioceptive signals in subjects with LBP. Hum Mov Sci. 2015;39:109-20. (DOI:10.1016/j. humov.2014.05.011) (PMID)

8. Ivanenko Y, Gurfinkel VS. Human Postural Control. Front Neurosci. 2018;12:171. (DOI:10.3389/fnins.2018.00171) (PMID) (PMCID)

9. Zackowski KM, Cameron M, Wagner JM. 2nd International Symposium on Gait and Balance in Multiple Sclerosis: interventions for gait and balance in MS. Disabil Rehabil. 2014;36(13):1128-32. (DOI:10.3109/0963828 8.2013.8333 06) (PMID)

10. Dibble LE, Lopez-Lennon C, Lake W, Hoffmeister C, Gappmaier E. Utility of disease-specific measures and clinical balance tests in the prediction of falls in persons with multiple sclerosis. J Neurol Phys Ther. 2013;37(3):99-104. (DOI:10.1097/NPT.0b013e3182a18460) (PMID)

11. Forsberg A, von Koch L, Nilsagård Y. Effects on Balance and Walking with the CoDuSe Balance Exercise Program in People with Multiple Sclerosis: A Multicenter Randomized Controlled Trial. Mult Scler Int. 2016;1-10. (DOI:10.1155 12016/7076265) (PMID) (MCID)

12. Normann B, Salvesen R, Christin Arntzen E. Group-based individualized core stability and balance training in ambulant people with multiple sclerosis: a pilot feasibility test-retest study. Eur J Physiother. 2016;18(3):173-8. (DOI:10.3109/2 1679169.2016.1170204)

13. Tarakci E, Yeldan I, Huseyinsinoglu BE, Zenginler Y, Eraksoy M. Group exercise training for balance, functional status, spasticity, fatigue and quality of life in multiple sclerosis: a randomized controlled trial. Clin Rehabil. 2013;27(9):813-22. (DOI:10.1177/0269215513481047) (PMID)

14. Cattaneo D, Rasova K, Gervasoni E, Dobrovodská G, Montesano A, Jonsdottir J. Falls prevention and balance rehabilitation in multiple sclerosis: a bi-centre randomised controlled trial. Disabil Rehabil. 2018;40(5):522-6. (DOI:10. 1080/09638288.2016.1258089) (PMID)

15. Soysal Tomruk M, Uz MZ, Kara B, İdiman E. Effects of Pilates exercises on sensory interaction, postural control and fatigue in patients with multiple sclerosis. Mul Scler Relat Disord. 2016;7:70-3. (DOI:10.1016/j.msard.2016.03.008) (PMID)

16. Kalron A, Rosenblum U, Frid L, Achiron A. Pilates exercise training vs. physical therapy for improving walking and balance in people with multiple sclerosis: A randomized controlled trial. Clin Rehabil. 2017;31(3):319-28. (DOI:10.11 77/0269215516637202) (PMID) 
17. Carling A, Forsberg A, Gunnarsson M, Nilsagård Y. CoDuSe group exercise programme improves balance and reduces falls in people with multiple sclerosis: A multi-centre, randomized, controlled pilot study. Mult Scler. 2017;23(10):1394-404. (DOI:10.1177/1352458516677591) (PMID) (PMCID)

18. Downs S. The Berg Balance Scale. J Physiother. 2015;61(1):46. (DOI:10.1016/j.jphys.2014.10.002) (PMID)

19. Wirth K, Hartmann H, Mickel C, Szilvas E, Keiner M, Sander A. Core stability in athletes: A Critical Analysis of Current Guidelines. Sports Med. 2017;47(3):401-14 (DOI:10.1007/s40279-016-0597-7) (MID)

20. Ketelhut NB, Kindred JH, Manago MM, Herbert JR, Rudroff T. Core muscle characteristics during walking of patients with multiple sclerosis. J Rehabil Res Dev. 2015;52(6):713 (DOI:10.1682/JRRD.2015.01.0006) (PMID)

21. Kjølhede T, Vissing K, Langeskov-Christensen D, Stenager E, Petersen T, Dalgas U. Relationship between muscle strength parameters and functional capacity in persons with mild to moderate degree multiple sclerosis. Mult Scler Relat Disord. 2015;4(2):151-8. (DOI:10.1016/j.msard.2015.01 .002) (

22. Dalgas U, Stenager E, Lund C, Rasmussen C, Petersen T, Sørensen $\mathrm{H}$, et al. Neural drive increases following resistance training in patients with multiple sclerosis. J Neurol. 2013;260(7):1822-32. (DOI:10.1007/s00415-013-6884-4) (PMID)

23. Huisinga JM, Filipi M, Stergiou N. Supervised resistance training results in changes in postural control in patients with multiple sclerosis. Motor Control. 2012;16:50-63. (DOI:10.1123/mcj.16.1.50) (PMID)

24. Hilfiker R, Vaney C, Gattlen B, Meichtry A, Deriaz O, Lugon-Moulin $\mathrm{V}$, et al. Local dynamic stability as a responsive index for the evaluation of rehabilitation effect on fall risk in patients with multiple sclerosis: a longitudinal study. BMC Res Notes. 2013;6:260. (DOI:10.1186/17560500-6-260) (PMID) (MCID)

25. Yahia A, Ghroubi S, Mhiri C, Elleuch M. Relationship between muscular strength, gait and postural parameters in multiple sclerosis. Ann Phys Rehabil Med. 2011;54(3):14455. (DOI:10.1016/j.rehab.2011.02.004) (PMID)

26. Cameron MH, Horak FB, Herndon RR, Bourdette D. Imbalance in multiple sclerosis: a result of slowed spinal somatosensory conduction. Somatosens Mot Res. 2008;25(2):113-22. (DOI:10.1080/08990220802131127) (PMID) (PMCID)

27. Gandolfi M, Geroin C, Picelli A, Munari D, Waldner A, Tamburin S, et al. Robot-assisted vs. sensory integration training in treating gait and balance dysfunctions in patients with multiple sclerosis: a randomized controlled trial. Front Hum Neurosci. 2014;8:318. (DOI:10.3389/fnhum.2014. 00318) (MID) (MCID)

28. Elwishy A. Effect of sensorimotor integration balance program in patients with Multiple Sclerosis: a single blinded randomized controlled study. Med J Cairo Univ. 2012;80(2).

29. Brichetto G, Piccardo E, Pedullà L, Battaglia MA, Tacchino A. Tailored balance exercises on people with multiple sclerosis: a pilot randomized, controlled study. Mult Scler. 2015;21(8):1055-63. (DOI:10.1177/1352458514557985) (PMID)

30. Hebert JR, Corboy JR, Manago MM, Schenkman M. Effects of vestibular rehabilitation on multiple sclerosis-related fatigue and upright postural control: a randomized controlled trial. Phys Ther. 2011;91(8):1166-83. (DOI:10.2522/ptj.2 0100399) (PMID)

\section{How to Cite This Article:}

Najafi B, Rajabi R, Seidi F, Golipoor Maemodan F. The Effect of Combined Training Protocol on Postural Control and Motor Functions of Individuals with Multiple Sclerosis. J Adv Med Biomed Res. $2019 ; 27$ (122) :43-49

\section{Download citation:}

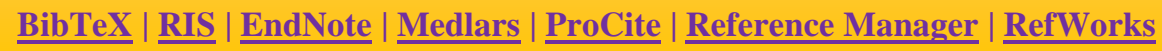

\section{Send citation to:}
Mendeley
Zotero
DefWorks RefWorks 